\title{
Article \\ Baseball Drag Measurements in Free Flight
}

\author{
Lloyd Smith ${ }^{1, *(1)}$ and Andrea Sciacchitano ${ }^{2}(\mathbb{D}$ \\ 1 School of Mechanical and Materials Engineering, Washington State University, Pullman, WA 99164, USA \\ 2 Department of Aerodynamics, Delft University of Technology, NE 2628 Delft, The Netherlands; \\ A.Sciacchitano@tudelft.nl \\ * Correspondence: lvsmith@wsu.edu; Tel.: +1-509-335-3221
}

check for

updates

Citation: Smith, L.; Sciacchitano, A. Baseball Drag Measurements in Free Flight. Appl. Sci. 2022, 12, 1416. https://doi.org/10.3390/app12031416

Academic Editor: Takeshi Asai

Received: 8 January 2022

Accepted: 25 January 2022

Published: 28 January 2022

Publisher's Note: MDPI stays neutral with regard to jurisdictional claims in published maps and institutional affiliations.

Copyright: (c) 2022 by the authors. Licensee MDPI, Basel, Switzerland. This article is an open access article distributed under the terms and conditions of the Creative Commons Attribution (CC BY) license (https:/ / creativecommons.org/licenses/by/ $4.0 /)$.
Featured Application: Authors are encouraged to provide a concise description of the specific application or a potential application of the work. This section is not mandatory.

\begin{abstract}
While baseball is a popular sport with a storied history, the aerodynamic properties of the seamed sports ball are not fully understood. Reported aerodynamic baseball behaviors are primarily based on force measurements from wind tunnels. The following describes a methodology to measure baseball drag in free flight from changes in its speed. The method relies on a high accuracy ball delivery device and speed measurement system. It avoids the large infrastructure, stinger attachment and blockage effects associated with wind tunnels. In the present work, we examined the baseball drag as a function of orientation and with spin. The drag values retrieved from the proposed method are in good agreement with radar and video measurements. However, they are lower than those reported in other wind tunnel measurements, which was attributed to differences in the balls that were tested or the stinger attachment.
\end{abstract}

Keywords: baseball aerodynamics; aerodynamic drag measurements; free-flight aerodynamics

\section{Introduction}

Major League Baseball (MLB) is the third most popular sport in the United States, with 20 million viewers during the 2017 World Series alone [1]. The home run is an important aspect of the game and is often normalized as the number of home runs per batted ball (HR/BB). From 1960 to 2015, the HR/BB varied from 0.03 to 0.04 , changing gradually from year to year with no apparent trend. The HR/BB increased abruptly starting in 2015, reaching 0.053 in 2017. The MLB commissioned a panel to study the unprecedented and dramatic change, which concluded that a small decrease in the ball's aerodynamic drag $(3 \%)$ was responsible for the increased offense [2]. The high sensitivity of HR/BB to ball drag has motivated increased scrutiny of baseball drag and the methods used to measure it.

The aerodynamic drag force on an object, $F_{d}$, is often measured in a wind tunnel. The object is held stationary on calibrated force sensors as a uniform airflow is introduced. The effects of drag can be described through a non-dimensional drag coefficient, $C_{d}$, while the aerodynamic effect of speed is often normalized by the Reynolds number, $\operatorname{Re}$ [3]. The drag coefficient is not constant but changes with $R e$. The relationship between $C_{d}$ and $\operatorname{Re}$ for smooth spheres was discovered independently by Lukyanov and Eiffel [4]. The drag of a smooth sphere as a function of speed has three distinct regimes [5]. In the subcritical regime, $\left(\operatorname{Re} \leq 2 \times 10^{5}\right) C_{d} \sim 0.5$, and it is nearly independent of $R e$. The mostly laminar flow separates from the sphere relatively early, resulting in a large wake and the highest drag of the three flow regimes. In the critical regime $\left(\operatorname{Re} \sim 3 \times 10^{5}\right)$, an abrupt decrease in drag occurs where $C_{d} \sim 0.1$, and is known as the "drag crisis". This phenomenon is caused by the generation of laminar separation bubbles, whereby the laminar boundary layer separates, transitions to turbulence in the free shear layer, reattaches onto the sphere's surface and then separates again, resulting in a smaller wake and the lowest drag of the 
three regimes [6]. In the supercritical regime $\left(\operatorname{Re}>3 \times 10^{5}\right)$ the boundary layer prior to separation is turbulent resulting in an intermediate drag in comparison to the other regimes. The drag coefficient increases gradually with $R e$ in the supercritical regime. Ball speeds representative of play are usually at the end of the drag crisis where flow is transitioning to fully turbulent.

Air speed is not the only factor affecting flow separation. Ball spin will cause the flow separation points to move, which can affect the drag and cause lift by what is known as the Magnus effect [7]. The spin tends to move the separation points and wake in the direction of the ball rotation. The imbalance in pressure from asymmetric separation points causes a lift force. The distance the separation points move is roughly proportional to the spin rate $[8,9]$. The roughness, including seams on sports balls, increases the sensitivity to spin. Roughness may cause a transition in the boundary layer from laminar to turbulent flow, which reduces the speed for the onset of the critical regime while increasing drag in the supercritical regime. The dimples of golf balls are carefully designed to reduce drag over speeds used in play. The seams of a baseball also encourage turbulence at lower speeds and can alter the location of the flow separation points.

The dependence of drag on ball orientation was studied in wind tunnels, as depicted in Figure 1, for $30 \mathrm{~m} / \mathrm{s}\left(R e=1.5 \times 10^{5}\right)$ [10]. Since the four-seam spin axis has two planes of symmetry, the drag dependence repeats four times per revolution. While wind tunnels are commonly used to measure the drag of sports balls, they have a potentially adverse interference effect. The support used to hold the ball stationary and measure aerodynamic forces can interrupt the airflow and alter the aerodynamic forces that are being measured. In order to avoid this undesirable interference effect, supports are often attached downstream of the object, which minimizes their effect. To study the effect of ball orientation, however, the ball is supported on its spin axis, close to the flow separation. It is not clear how these attachments affect the location of the flow separation and drag measurements.

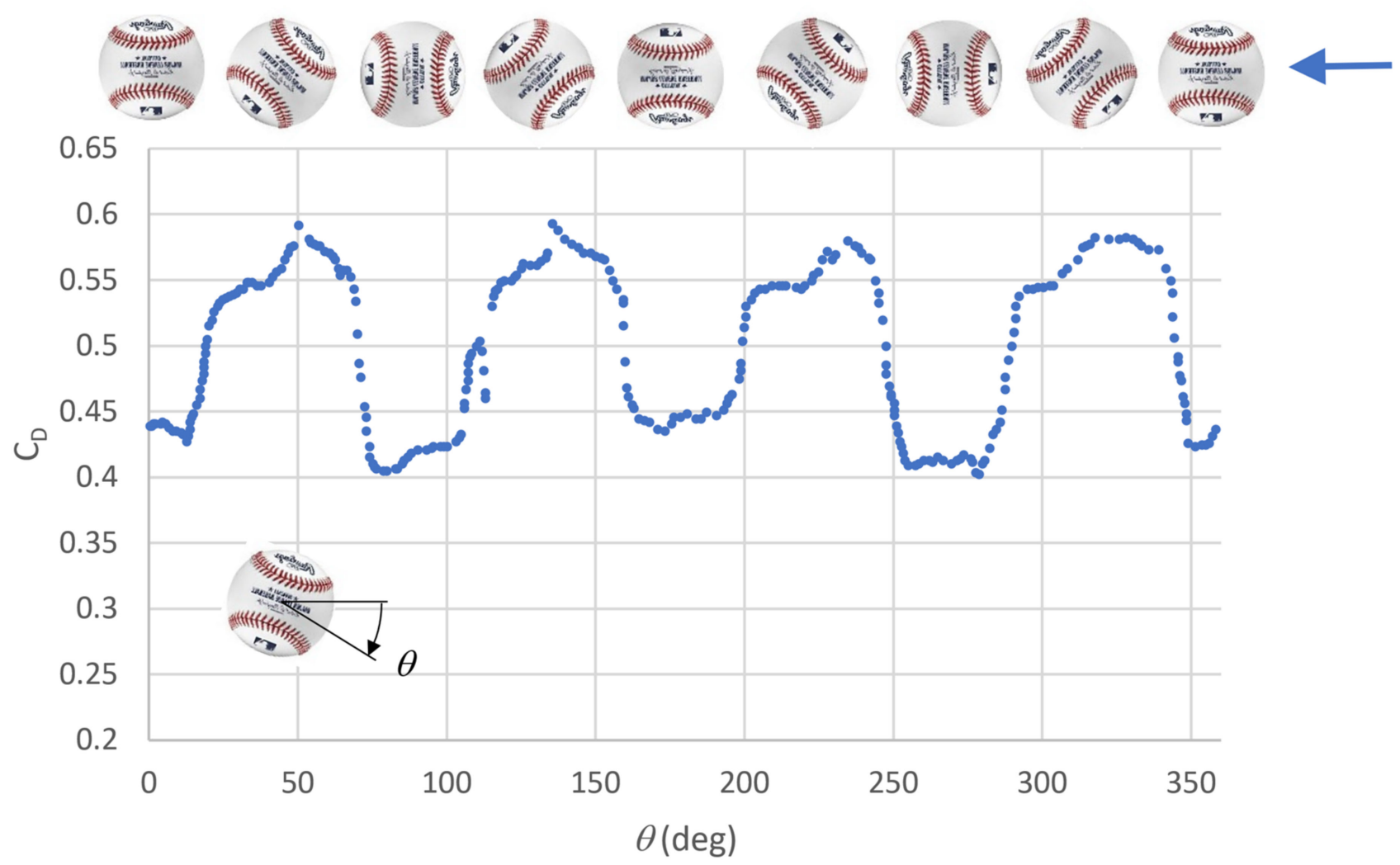

Figure 1. Wind tunnel results show the effects of seam orientation on the drag coefficient from [10]. 
Baseballs have a characteristic white leather cover formed from two panels that are sewn together by hand with a single continuous seam. While they are similar in appearance, the construction and quality of baseballs vary widely between models. This work considers the Major League Baseball (MLB), given the high interest in ball response at this level of play and its high repeatability and quality. The effects of the drag are considered for $\operatorname{Re}=170,000(36 \mathrm{~m} / \mathrm{s})$, which is representative of play. Wind tunnel measurements of non-spinning MLB baseballs have found its drag to be as low as $C_{d}=0.3$ [11] and as high as $C_{d}=0.6$ [12]. While baseball drag in play is likely closer to $C_{d}=0.35[13,14]$, the range in $C_{d}$ from wind tunnel measurements suggests that it is challenging, even for aerodynamic specialists to measure.

The first free-flight baseball drag measurements occurred during the 1996 Olympics [15]. Balls were tracked with two $120 \mathrm{~Hz}$ cameras at a resolution of $640 \times 480$ pixels. While the drag crisis from this work was likely overestimated due to low camera resolution $\left(C_{d}=0.15\right)$, it was an important advancement in aerodynamic measurement. In 2006, videobased ball tracking systems were installed in every Major League Baseball Park (PITCHf/x, Sportvision). The three components of each pitch trajectory are fit to second-order (constant acceleration) polynomials using a least-squares fit. The systems were primarily intended to track pitch speed, pitch movement and the strike zone location, but drag could also be extracted from the publicly available fit parameters. Drag measurements were susceptible to noise and environmental effects inherent with ballparks. These shortcomings were largely overcome by averaging the large amount of data collected over multiple seasons. One study reported $C_{d}=0.346$ [16]. Another study measured the launch conditions and landing locations from balls projected $120 \mathrm{~m}$ from a pitching machine in an enclosed park and found $C_{d}=0.36$ [17]. The balls were projected at $43 \mathrm{~m} / \mathrm{s}$, slowing to $27 \mathrm{~m} / \mathrm{s}$ at their apex, with an average speed of $36 \mathrm{~m} / \mathrm{s}$ over their trajectory.

The general agreement in $C_{d}$ between the wind tunnel (no spin) and free flight (with spin) measurements is noteworthy. The drag coefficient is known to increase with ball spin, although the dependence is weak $[13,18]$. The agreement with the balls projected in the stadium also show that average drag properties have utility in describing ball trajectories. The following proposes a laboratory system to measure the drag of baseballs in free flight. The system avoids the large infrastructure and the potential effects of the sting and wall interference associated with wind tunnels. Baseball drag is measured as a function of orientation and compared to the drag of spinning balls.

\section{Methods}

Balls were projected horizontally at $36 \pm 1 \mathrm{~m} / \mathrm{s}\left(\operatorname{Re}=1.8 \times 10^{5}\right)$ using a pneumatically actuated piston, as shown in Figure 2. Ball speed was measured from a speed sensor from the time for the ball to pass between light screens (iBeam, ADC) spaced $0.4 \mathrm{~m}$ apart. Ball acceleration, $a$, was found from subsequent speed measurements $\left(V_{1}\right.$ and $\left.V_{2}\right)$, taken $D=3 \mathrm{~m}$ apart along the ball's trajectory, or

$$
a=\frac{V_{2}^{2}-V_{1}^{2}}{2 D}
$$

The drag force was found from the ball's mass (145 g) and acceleration. The measured diameter of each ball was used to find $C_{d}$. The drag coefficient from three balls was taken from the average of four measurements per ball.

Balls are commonly projected with spin from a wheeled pitching machine. Rubber wheels, rotating at different speeds, accelerate the ball and impart spin. Baseballs used in play have a leather cover, which is abraded by the rapid acceleration from spinning pitching machine wheels. The aerodynamic properties of baseballs roughened by the pitching machine can be significantly different from those used in play. In this work, the spin was imparted to balls using a cradle attached to the end of the pneumatic piston [19]. The cradle, shown in Figure 3, had an opposing high and low friction surface, which imparted spin as the piston reached the end of its travel and the ball rolled out of the cradle. 
The spin rate increased with the cradle length. By adjusting the ball's position in the cradle prior to firing, the spin rate was controlled. The orientation of the spin axis was controlled by the orientation of the cradle prior to firing. In this work, a horizontal spin axis was used to create a backspin and lift. Visual inspection and repeated drag measurements demonstrated an ability to impart spin without damaging the ball or altering its drag.

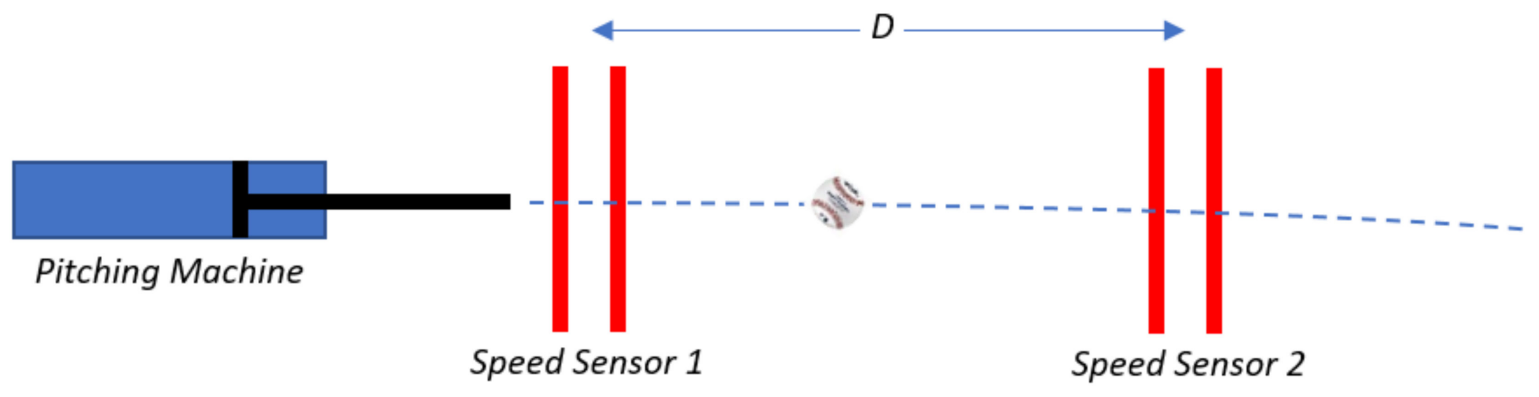

Figure 2. Schematic of apparatus used to project the baseball and measure its speed at two locations along its trajectory.

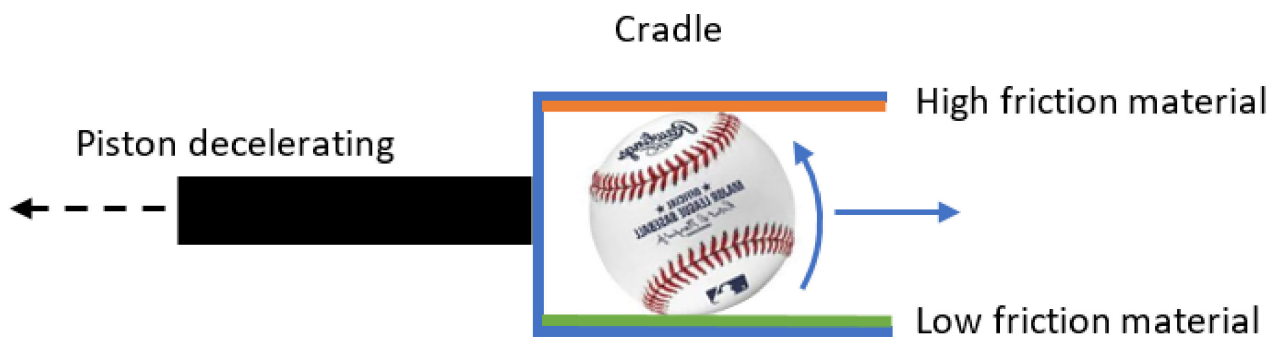

Figure 3. Schematic of the cradle attached to the pneumatic piston, showing spin imparted to the baseball as the piston decelerates.

The accuracy of the drag measurement is a function of the air density, light screens, ball geometry and ball mass. The distance between the screens was controlled to within $0.2 \mathrm{~mm}$, and the seam on the baseball was $0.9 \mathrm{~mm}$ high. If the ball rotates while passing through the screens, the seam can add an error to the drag measurement. The screen spacing error, the $36 \mathrm{~m} / \mathrm{s}$ ball speed and $0.4 \mathrm{~m}$ screen spacing used here resulted in $\Delta C_{d}=0.004$. The distance between screen pairs, $D$, was within $3 \mathrm{~mm}$, where $\Delta C_{d}=0.0003$. The average ball mass was $145 \mathrm{~g}$ and was within $15 \mathrm{mg}$, where $\Delta C_{d}=0.002$. The average ball diameter was $75 \mathrm{~mm}$ and measured with a pi tape to within $0.2 \mathrm{~mm}$, where $\Delta C_{d}=0.003$. Temperature affects air density, which was within $1^{\circ} \mathrm{C}$ along the ball path, where $\Delta C_{d}=0.002$. The time between successive light screens was measured at $80 \mathrm{MHz}$ (VG03, ADC), making the error in time negligible in comparison to the other factors considered here. By assuming the errors to be independent and normally distributed, their cumulative contribution can be estimated by the sum of their squares as $\Delta C_{d}=0.006$.

Ball orientation was measured by tracking three markers placed on each ball (ROMLB, Rawlings), as shown in Figure 4. The ball trajectory was recorded at $1000 \mathrm{fps}$ and $720 \times 1280$ pixels $($ V711, Phantom). Ball orientation was obtained from the inclination of the colinear points, while the spin rate was taken from the time between images of different orientations. In order to obtain an independent measure of drag, the ball trajectory could have been tracked with high-speed cameras. In order to measure ball orientation, a small field of view with a high camera resolution was needed. Unfortunately, the short ball trajectory observed in the video field of view prevented a meaningful measure of acceleration for comparison with the speed sensors. 


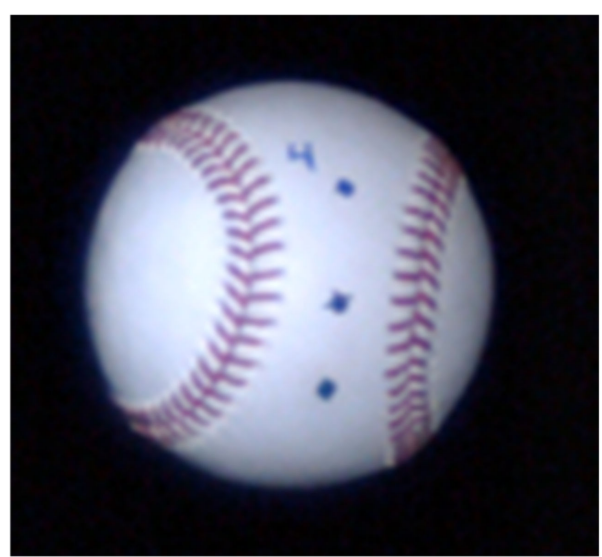

Figure 4. Image of tracking dots on baseball that were used to measure spin.

Particle Image Velocimetry (PIV) measurements were conducted in the Aerodynamics Laboratory of TU Delft to visualize the baseballs' wake in free flight for the non-spinning case. The air was seeded with micron-size water-glycol particles produced by a Safex seeding generator. The particles were illuminated via a Quantronix Darwin Duo Nd:YLF laser $(25 \mathrm{~mJ}$ pulse energy at $1 \mathrm{kHz}, 527 \mathrm{~nm}$ wavelength). Images were recorded by a LaVision HighSpeedStar6 camera (CMOS, $1024 \times 1024$ pixels, $20 \mathrm{~mm}$ pixel pitch, 12 bit) in frame-straddling mode $(\Delta \mathrm{t}=40 \mathrm{~ms})$, at a repetition rate of $500 \mathrm{~Hz}$. The camera used a Nikkor lens with a focal length of $60 \mathrm{~mm}$ and an aperture $\mathrm{f}$ stop of 2.8. The image magnification was $M=0.12$, resulting in a digital image resolution of $0.166 \mathrm{~mm} /$ pix. The images were processed using the cross-correlation-based algorithm (LaVision, DaVis 8.4) with image deformation and interrogation windows of $32 \times 32$ pixels with a $75 \%$ overlap factor.

\section{Results and Discussion}

The drag coefficient for the non-spinning case is shown as a function of orientation (using a four-seam spin axis) for three new baseballs in Figure 5. Each ball was projected between 94 and 108 times, and each projection had a unique orientation. Given the geometric symmetry of the four-seam spin axis, only orientations between 0 and $90^{\circ}$ were measured. The ball orientation shows a consistent dependence on drag, with a minimum at 0 and $90^{\circ}$ and a maximum at $45^{\circ}$. The peak drag at $45^{\circ}$ is not unexpected, as the seams likely induce a flow separation location that maximizes the wake size at this orientation, as observed elsewhere $[10,20]$. This is confirmed by the velocity fields illustrated in Figure 6 for the orientations of $85^{\circ}$ (Figure 6-left) and $45^{\circ}$ (Figure 6-right). At $\theta=85^{\circ}$, the flow remains attached to the baseball's surface up to $\pm 130^{\circ}$ from the stagnation point, producing a narrow wake and low aerodynamic drag. Conversely, for the $\theta=45^{\circ}$ orientation, flow separation occurs at $\pm 100^{\circ}$ from the stagnation point, yielding a wide wake and high aerodynamic drag.

The data in Figure 5 were averaged to allow comparison to the drag of balls projected with spin. Since the number of shots at each orientation was not evenly distributed, a simple average of the data would bias the drag toward the 0 and $90^{\circ}$ orientations. Drag as a function of ball orientation was fit to a fourth-order polynomial. The average drag coefficient from this fit was 0.348 . In order to obtain a spinning drag coefficient, balls 1 , 2 and 3 were projected through the same drag measuring system with a $2500 \pm 250 \mathrm{rpm}$ spin rate, using the cradle described in Figure 3 . The average drag coefficient from these balls was 0.358 , in agreement with drag found elsewhere $[13,14,16,17]$. The spinning and non-spinning average drag coefficients are in close agreement, as was observed in the comparison of non-rotating wind tunnel and rotating free flight drag measurements presented in the introduction. The spinning drag measurements $(0.358)$ are slightly higher than the non-spinning results (0.348), consistent with the effects of spin on drag [18]. 


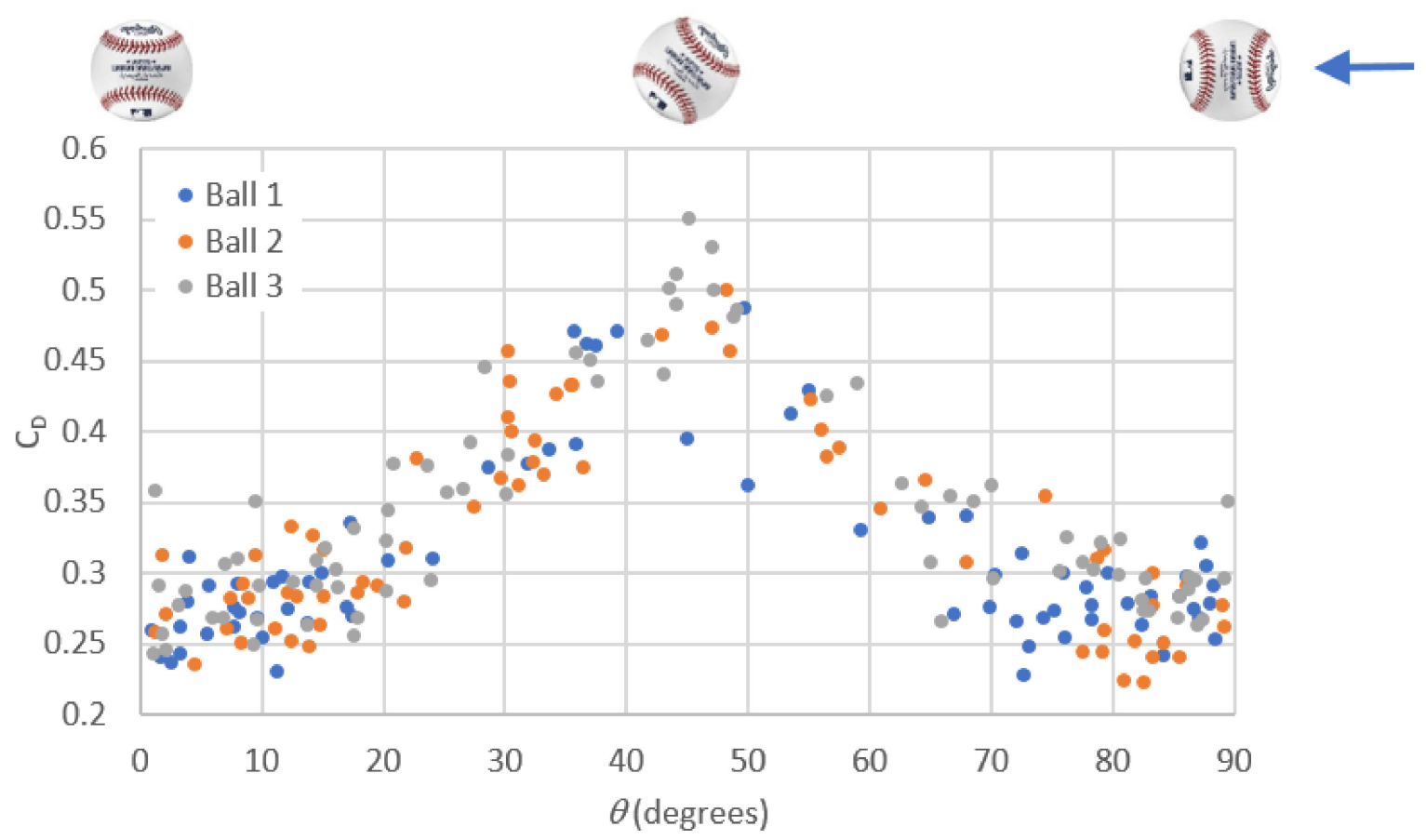

Figure 5. Scatter plot of the drag coefficient of three MLB baseballs without spin measured in free flight.
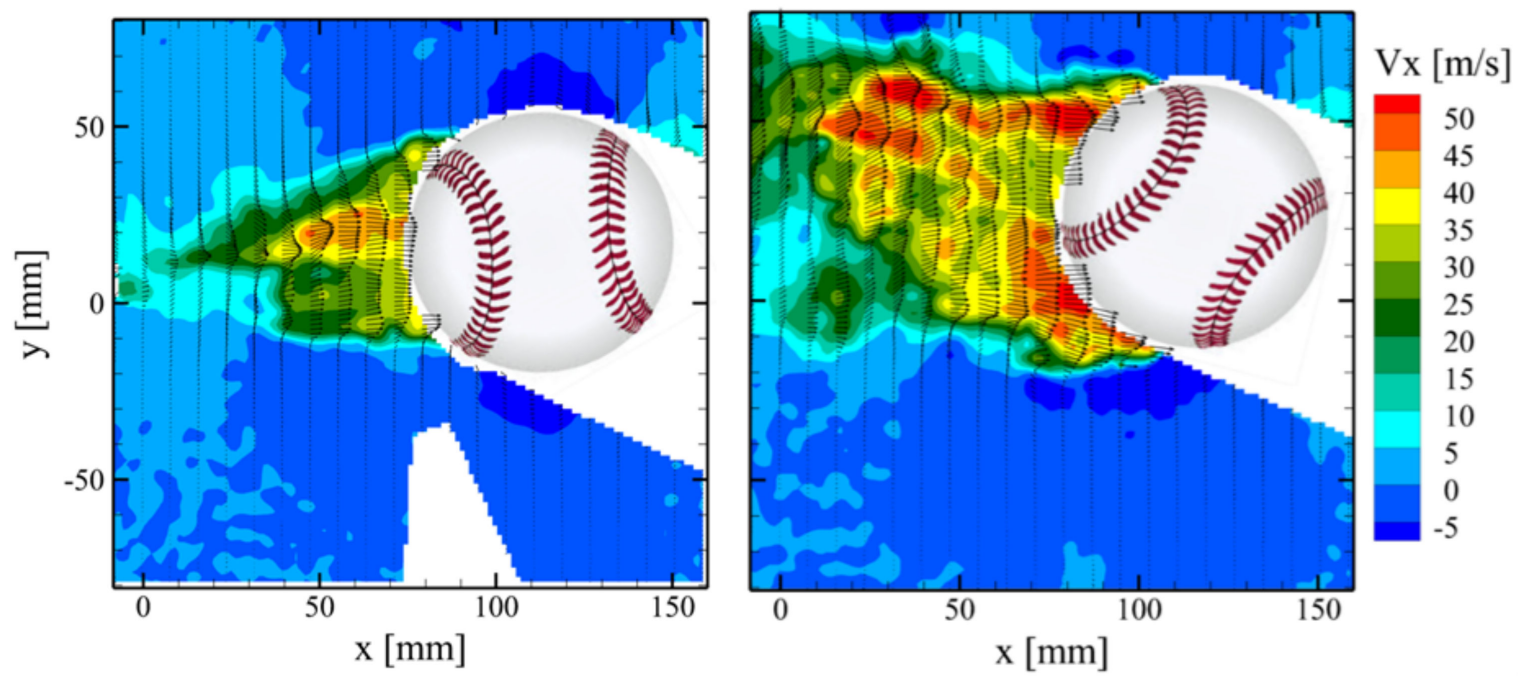

Figure 6. Instantaneous velocity fields in the wake of non-spinning baseballs traveling left to right in free flight. (Left): $\theta=85^{\circ}$; (Right): $\theta=45^{\circ}$. The blank region at the bottom of the left figure is due to erroneous vectors from measurement noise, which were blanked out for clarity.

The data in Figure 5 were smoothed using a moving five-point average, as shown in Figure 7. The dotted lines represent the maximum and minimum over each five-point averaging span. The $0-90^{\circ}$ symmetry condition was applied to the wind tunnel results from Figure 1 (taken from [10]) and are plotted in Figure 7 using the same five-point averaging scheme applied to the free flight drag results. The wind tunnel and free flight drag measurements show a similar dependence on orientation, in that a peak drag coefficient is observed near $45^{\circ}$, and minima near 0 and $90^{\circ}$. The wind tunnel measurements appear to be more repeatable than the free flight measurements, which is attributed to the higher statistical convergence of the wind tunnel measurements and the different number of balls 
used for each study (the wind tunnel tests used one ball, while the free flight tests used three balls).
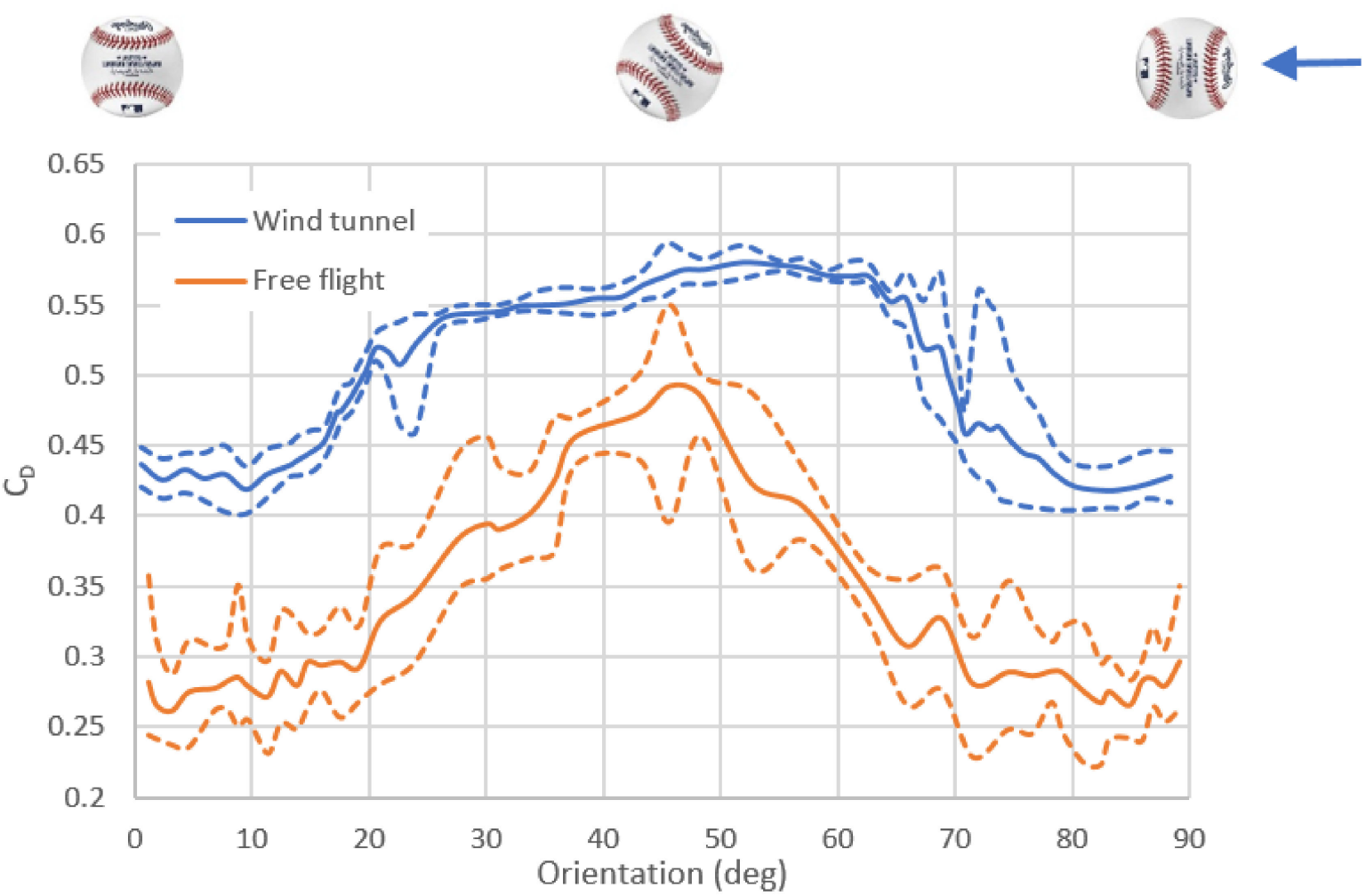

Figure 7. A comparison of the MLB drag coefficient for balls without spin as a function of orientation in free flight and a wind tunnel (from [10]).

Drag from the wind tunnel tests was higher than that found from the free flight. The wind tunnel tests were performed at a slower speed than the free flight tests (30 vs. $36 \mathrm{~m} / \mathrm{s}$ ). The ball used in the wind tunnel tests was identified as "commercially available", and may have had higher seams than the MLB balls used in the free-flight tests. These differences, along with the differences of the experimental setups (namely, the presence of model support in the wind tunnel measurements), are likely responsible for the lower drag measured in free flight.

The wind tunnel results exhibit a plateau between about 25 and $65^{\circ}$, while the free flight drag tends to peak at $45^{\circ}$, with no evidence of a plateau. The difference could be due to the different seam heights of the balls for each study or to a flow disturbance from the stinger used to support and rotate the ball. The stinger could fix the flow separation on the side of the ball, a location on the ball that maximizes drag.

\section{Summary and Conclusions}

The foregoing has presented a novel laboratory means of measuring ball drag in free flight. Using the proposed method, drag from spinning balls agreed with wind tunnel and other free flight measures of drag. Ball drag was also measured as a function of orientation, which generally agreed with similar measures from a wind tunnel. A high drag region at $45^{\circ}$ lingered over a greater range in the wind tunnel compared to that measured in free flight. The differences between the wind tunnel and free flight may be due to ball attachment effects, which cannot be completely corrected since the attachment location may bias the flow separation location. Based on the results presented in this work, it is concluded that free-flight tests reproduce with a larger degree of realism the flow physics around a moving baseball and should be considered to complement wind tunnel tests whenever possible. 
Author Contributions: Conceptualization, L.S; methodology, L.S.; validation, L.S.; formal analysis, L.S.; investigation, L.S. and A.S.; resources, L.S. and A.S.; data curation, L.S.; writing-original draft preparation, L.S.; writing-review and editing, A.S.; visualization, L.S. and A.S. All authors have read and agreed to the published version of the manuscript.

Funding: No external funding was used for this work.

Acknowledgments: The support of Taylor Tosaya to the PIV experiments is kindly acknowledged.

Conflicts of Interest: The authors declare no conflict of interest.

\section{References}

1. Astros-Dodgers Game 6 Among Top World Series Games Since 2004. Sports Media Watch, 2 November 2017. Available online: https:/ / www.sportsmediawatch.com/2017/11/world-series-ratings-game-6-fox/(accessed on 7 January 2022).

2. Albert, J.; Bartroff, J.; Blandford, R.; Brooks, D.; Derenski, J.; Goldstein, L.; Hosoi, A.; Lorden, G.; Nathan, A.; Smith, L. Report of the Committee Studying Home Run Rates in Major League Baseball. 12 April 2018. Available online: illinois.edu (accessed on 7 January 2022).

3. Panton, R.L. Incompressible Flow; John Wiley \& Sons: Hoboken, NJ, USA, 2013.

4. Birkhoff, G. Hydrodynamic; Princeton University Press: Princeton, NJ, USA, 2015.

5. Achenbach, E. Experiments on the flow past spheres at very high Reynolds numbers. J. Fluid Mech. 1972, 54, 565-575. [CrossRef]

6. Taneda, S. Visual observations of the flow past a sphere at Reynolds numbers between 104 and 106. J. Fluid Mech. 1978, 85, 187-192. [CrossRef]

7. Magnus, G. Ueber die Abweichung der Geschosse, und: Ueber eine auffallende Erscheinung bei rotirenden Körpern. Ann. Phys. 1853, 164, 1-29. [CrossRef]

8. Alaways, L. Aerodynamics of a curve-ball: The Sikorsky/Lightfoot lift data. Eng. Sport 2008, 7, 429.

9. Watts, R.G.; Ferrer, R. The lateral force on a spinning sphere: Aerodynamics of a curveball. Am. J. Phys. 1987, 55, 40-44. [CrossRef]

10. Higuchi, H.; Kiura, T. Aerodynamics of knuckle ball: Flow-structure interaction problem on a pitched baseball without spin. J. Fluids Struct. 2012, 32, 65-77. [CrossRef]

11. Mehta, R.; Pallis, J. Sports ball aerodynamics: Effects of velocity, spin and surface roughness. In Materials and Science in Sports; Froes, F., Haake, S., Eds.; The Minerals, Metals \& Materials Society: Warrendale, PA, USA, 2001; pp. $185-197$.

12. Alam, F.; Ho, H.; Chowdhury, H.; Subic, A. Aerodynamics of baseball. Procedia Eng. 2011, 13, 207-212. [CrossRef]

13. Adair, R.K. The Physics of Baseball, 3rd ed.; Harper \& Row, Publishers Inc.: New York, NY, USA, 2002; p. 8.

14. Alam, F.; Hoa, H.; Smith, L.; Subic, A.; Chowdhury, H.; Kumara, A. A study of baseball and softball aerodynamics. In Proceedings of the 9th Conference of the International Sports Engineering Association (ISEA), Amherst, MA, USA, July 2012; Volume 34, pp. 86-91.

15. Alaways, L.; Mish, S.; Hubbard, M. Identification of release conditions and aerodynamic forces in pitched-baseball trajectories. J. Appl. Biomech. 2001, 17, 63-76. [CrossRef]

16. Kagan, D.; Nathan, A. Simplified Models for the Drag Coefficient of a Pitched Baseball. Phys. Teach. 2014, 52, 278-280. [CrossRef]

17. Nathan, A.; Kensrud, J.; Smith, L.; Lang, E. How Far Did That Fly Ball Travel (Redux)? Baseball Prospectus, 9 December 2014. Available online: https://www.baseballprospectus.com/news/article/25167/prospectus-feature-how-far-did-that-fly-balltravel-redux/(accessed on 7 January 2022).

18. Kensrud, J. Determining Aerodynamic Properties of Sports Balls In Situ. Master's Thesis, Washington State University, Pullman, WA, USA, 2010. Available online: https://rex.libraries.wsu.edu/esploro/outputs/99900525114301842 (accessed on 7 January 2022).

19. Lyu, B.; Kensrud, J.; Smith, L. The reverse Magnus effect in golf balls. Sports Eng. 2020, 23, 7. [CrossRef]

20. Smith, A.; Smith, B. Using baseball seams to alter a pitch direction: The seam shifted wake. J. Sports Eng. Technol. 2021, 235, 21-28. [CrossRef] 